\title{
New Perspectives on the Translation of Advertising
}

\author{
Laura Cruz García ${ }^{1}$ \\ Universidad de Las Palmas de Gran Canaria
}

The language of advertising has for long proved a profitable resource for the teaching and learning of foreign languages at different educational levels, as well as for cultural and discourse studies, among others. Research paths and possibilities in the field are usually concerned with the domain of morphosyntax, pragmatics and semiotics in their widest sense, and the study of a wide range of specific language devices including terminology, loanwords and neologisms, the imperative mode, and images, for example. The peculiarities of advertising messages (combining verbal and non-verbal elements), their predominant persuasive function, and the large variety of texts produced in this sector are solid reasons for language trainers and scholars' interest.

When it comes to the translation of advertising texts, language in this field offers more, and more varied ways of exploitation, analysis, and applications. The existing publications focusing on this area of study are evidence of the large translation researchers' attention it has drawn. For instance, the topic has been examined from the point of view of the product type being advertised, the potential addressees and the cultural patterns that get in contact in the translation process, the advertising and translation strategies used to achieve the objectives, the medium constraints, as well as the role of the translator (cf. Adams, 2010; Adab, 2000; Boivineau, 1972; Bueno García, 2000; Cortés de los Ríos, 2001; Cruz García, 2005 , 2013; Cómitre Narváez: 2000, 2009; De Mooij, 2004; Guidere, 2009; Sidiropoulou, 1998, 2008; Valdés Rodríguez, 2004; among many others).

\footnotetext{
Universidad de Las Palmas de Gran Canaria, Departamento de Filología Moderna, Facultad de Traducción e Interpretación, Pérez del Toro, 1, 35003 Las Palmas de Gran Canaria (España).

Email: laura.cruz@ulpgc.es
} 
The six articles in this Special Issue exhibit various stances to the translation of advertising, which is looked at by their authors from very different perspectives and with varied and innovative applications. All of them constitute valuable examples of interdisciplinary approaches to the topic.

The first paper, by Isabel Cómitre Narváez, is devoted to subtitling for the deaf and hard of hearing, as a type of inter-semiotic translation (from oral into written mode). She highlights the fact that, while in countries such as France and Spain, the national accessibility guidelines for the adaptation of audiovisual texts refer to the way films, documentaries, news, etc. should be made accessible for the deaf and the hard of hearing (through subtitling) as well as for the visually impaired (through audio description), no mention is made of advertising texts. Concerned about deaf and hard of hearing people's need to access TV adverts, the lack of legislation, and the difficulties this task involves, she focuses on the importance of producing subtitles for these particular addressees in order to convey advertising messages both in a creative and inclusive way. Bearing in mind that a TV advertisement bases its persuasive function on the combination of verbal and non-verbal elements, and the wide range of meanings conveyed through the latter, she refers to the growing use of emoticons. In her view, they can be really useful in the creation of audiovisual adverts which, together with adapted subtitles, can reach this type of addressee with special needs. In order to show the relevance of this task, she analyses the French version of the commercial for the product Kinder Bueno by the Ferrero group and the subtitled version in the same language.

In the second paper, Montse Corrius Gimbert, Marcella De Marco and Eva Espasa Borrás describe the results of an interdisciplinary and interuniversity study. The authors seek to resolve whether and to what extent students of Translation and of Advertising are gender aware when they deal with the translation and the production of non-profit as opposed to commercial advertising. Three groups of students (undergraduate versus postgraduate) of two different universities (the Spanish University of Vic-Central University of Catalonia, and the British London Metropolitan University) participated in the study. By means of a selection of nonprofit advertisements presenting gender-related concerns, which these students analyzed and translated, the authors want to find out whether, when translating and producing these adverts, the students pursue a balance between advertising effectiveness and gender equality. These findings can shed light on the degree of professional responsibility the students believe they have towards the transmission of gender principles and their awareness of the impact this could have on the social perception of gender.

In the third contribution, $\mathbf{M}^{\mathrm{a}}$ Enriqueta Cortés de los Ríos and Ana Corral Hernández explore the discourse in the promotion of health and beauty tourism in 
the Spanish region of Andalusia through tourism websites, as an alternative to the traditional promotion of sun and sea. Through the analysis of a corpus of websites advertising health and beauty centres, they offer a general view of this type of discourse in order to identify and describe its main distinctive features. Taking into account the persuasive nature of these advertising texts, they deepen into lexicalmorphological elements, such as the use of specialized vocabulary, positive adjectives, loanwords, and direct address to the reader, for example. As for the syntactic elements, they look at the role of imperatives, present and future tenses, and ellipsis, to name but a few. Metaphors, hyperboles, personifications, etc. are some of the stylistic resources these texts deploy in order to reach their aims, i.e. to influence potential tourists and to motivate them to visit the health and beauty centres. Since the rapid development of health and beauty tourism has given rise to a new type of specialized discourse, the authors consider that the results of this study can contribute both to professional and to trainee translators who, quite probably, may have to face this text type in their future professional careers.

Also within the field of promotional tourist texts, Adrián Fuentes Luque explores the role image plays in Spain's tourist advertising at an international level. To do so, he presents a case study of a set of translated institutional campaigns by Turespaña from 1984 to 2011, focusing specifically on the slogans used, which he analyses thoroughly. In order to support his study, he carries out and describes a small-scale reception study among a group of English-speakers, the results of which show the views of potential and actual tourists regarding the analysed advertising campaigns. Concerned about the quality of the translations produced in the Spanish tourist sector nowadays, where more than often the translation is commissioned to a nonexpert, the author highlights and defends the role of the professional translator as a mediator, and as an intercultural analyst and thus a key component in the process of transferring the brand of a country to peoples of other cultures. In this paper he stresses the importance of stereotypes, perceptions, and cultural references in international tourist advertising as crucial factors whose knowledge and treatment by the translator can determine the success or failure of an advertising campaign.

In the fifth article, by José Luis Martí Ferriol and $\mathbf{M}^{\mathbf{a}}$ Rosario Martí Marco, the teaching experience carried out and described revolves around a text type to which little scholarship attention has been paid in advertising: the film trailer. The inclusion of this text type in the domain of advertising is aptly justified by the authors, who offer a succinct but useful review of the genre as an audiovisual advertising text. The students involved in this practical approach were those enrolled in a course of German language for translators, dealing with linguistic and cultural contrasts, in the Degree of Translation and Interpreting at the Universidad de Alicante during two academic years (2014-2015 and 2015-2016). They practiced both direct and reverse 
subtitling. In this context, three specific fields seem to converge in their study, namely advertising translation, audiovisual translation (through subtitling), and language teaching and learning. The results of their inquiry revealed the students' concern with the process of subtitling with respect to the textual genre involved, and also their high degree of motivation with this task.

In the last article of this volume, Cristina Valdés Rodríguez deals with the translation of advertising from the scope of two strategies that are apparently contradictory, i.e. globalization and localization, and the way these economic and social phenomena influence the production and spread of advertising messages at a global and at an international level. Since, when translating advertising texts, both verbal and non-verbal elements are to be transferred either by means of standardization or by means of adaptation, the author points out the concepts of culture and potential consumers (as the addressees of these messages) as fundamental in the process. Through the description and analysis of representative examples of recent printed, television and online adverts by some well-known brands, she identifies the strategies used in each case and the difficulties found by the translator. She refers to the translator of advertising texts as the communicator of advertising messages, a crucial component of the marketing transactions and communication.

This Special Issue is proof overall of the richness of the discipline with respect to research paths still under exploration. We sincerely hope that this Issue will represent motivation for newcomers in the field, but mainly that it will constitute ground for further research and discussion.

\section{References}

Adab, B. (2000). Towards a More Systematic Approach to the Translation of Advertising Texts. In A. Beeby, D. Esinger \& M. Presas (eds.), Investigating Translation (223-234). Amsterdam/Philadelphia: John Benjamins.

Adams, H. (2010). Press Adverts for Financial Products in the UK and Spain: A Contrastive Análisis. Doctoral thesis, unpublished. Las Palmas de Gran Canaria: Universidad de Las Palmas de Gran Canaria.

Boivineau, R. (1972): L'A.B.C. de l'adaptation publicitaire. Meta. Journal des Traducteurs. 17(1): 5-28.

Bueno García, A. (2000). Publicidad y Traducción. Soria: Diputación Provincial de Soria. 
Cómitre Narváez, I. (2000). Traducción y publicidad. Aproximación a una estrategia traslativa (francés-español). Tesis doctoral. Málaga: Universidad de Málaga.

Cómitre Narváez, I. (2009). Doblaje audiovisual y publicidad. Reflexiones en torno al concepto de manipulación. Translation Journal, 13(3). $<$ http://translationjournal.net/journal/49doblaje.htm>

Cortés De Los Ríos, E. (2001): Nuevas perspectivas lingüísticas en la publicidad impresa anglosajona. Almería: Universidad de Almería.

Cruz García, L. (2003). Características diferenciales de la traducción publicitaria. El papel del traductor de anuncios. In L. Lorenzo \& A. Pereira (eds.), Traducción subordinada III: traducción y publicidad (pp. 17-28). Vigo: Servicio de Publicaciones de la Universidad de Vigo.

Cruz García, L. (2013). Copy Adaptation or how to Translate a Source Product for a Target Market. Meta. Journal des Traducteurs, 58(2), 347-372.

De Mooij, M. (2004). Translating Advertising. Painting the Tip of an Iceberg. The Translator, 10(2), 179-198.

Guidère, M. (2009). De la traduction publicitaire à la communication multilingue. Meta 54(3): 417-430.

Sidiropoulou, M. (1998). Advertising in Translation: English vs. Greek. Meta. Journal des Traducteurs, 43(2): 191-204.

Sidiropoulou, M. (2008). Sticky Captions: Genre-internal Variation in Print-based Ad Translating. Meta. 53(3): 471-489.

Valdés Rodríguez, C. (2004): La traducción publicitaria: comunicación y cultura. Bellaterra/ Castelló de la Plana/Barcelona/València: Universitat de València, Universitat Jaume I, Universitat Pompeu Fabra, Universitat Autònoma de Barcelona. 